Revista Temas Socio Jurídicos Vol. $36 \mathrm{~N}^{\circ} 72$ Enero - Junio de 2017

pp. $157-196$

ISSN 0120-8578

ISSN electrónico: 2590-8901

\title{
LA INSPECCIÓN AMBIENTAL, LA EVALUACIÓN DE IMPACTO AMBIENTAL, LA AUTORIZACIÓN AMBIENTAL Y LA AUDITORÍA AMBIENTAL
}

\author{
Alcides Antúnez Sánchez*
}

Recibido: Enero 4 de 2017

Aprobado: Abril 12 de 2017

\section{RESUMEN}

Los avances en la política ambiental y la gestión ambiental en las organizaciones empresariales han permitido articular estrategias de conservación y aprovechamiento de los recursos naturales y del ambiente como paradigmas de la política ambiental de los Estados. Estos avances han sido inclusivos al desarrollo normativo desde los textos constitucionales hasta las disciplinas de las ciencias jurídicas para su protección, donde se establecen derechos ambientales, inclusivos de la participación ciudadana para alcanzar el desarrollo sostenible. Se ejecuta un análisis de los instrumentos de tutela ambiental, vinculados al control público ambiental -evaluación de impacto ambiental, inspección ambiental, licencia ambiental y auditoría ambiental-. Por tales razones, el objetivo del artículo es sistematizar los elementos que configuran a los instrumentos de tutela ambiental (evaluación de impacto ambiental, inspección ambiental, licencia ambiental y auditoría ambiental) para delimitar sus puntos de conexión entre estos como parte de la política ambiental en pos de alcanzar una adecuada gestión ambiental sostenible.

Palabras clave: gestión ambiental, tutela ambiental, instrumentos de mercado de carácter cooperador. 


\title{
THE ENVIRONMENTAL INSPECTION, THE EVALUATION OF ENVIRONMENTAL IMPACT, THE ENVIRONMENTAL AUTHORIZATION AND THE ENVIRONMENTAL AUDITING
}

\begin{abstract}
Progress in environmental policy and environmental management in business organizations has allowed to articulate strategies of conservation and to use natural and environmental resources as paradigms of the state environmental policy. These accomplishments have been incorporated into constitutional texts and have become part of the disciplines of the judicial sciences for their protection, which include environmental rights that demand civic participation to attain sustainable development. It is carried out an analysis of Instruments of environmental tutelage linked to the environmental public control, environmental impact assessment, environmental inspection, environmental license and environmental auditing. These are the reasons for which the objective of this article is to systematize the elements that constitute the instruments of environmental tutelage (environmental impact assessment, environmental inspection, environmental license and environmental auditing) to delimit their points of connection as part of the environmental policy in order to attain environmental sustainability.
\end{abstract}

Key words: Environmental management, environmental tutelage, instruments of collaborative markets.

\section{A INSPEÇÃO AMBIENTAL, A AVALIÇÃO DE IMPACTO AMBIENTAL, A AUTORIZAÇÃO AMBIENTAL E A AUDITORIA AMBIENTAL}

\section{RESUMO}

Os avanços na política ambiental e gestão ambiental em organizações empresariais tem permitido articular estratégias de conservação e aproveitamento dos recursos naturais e do meio ambiente como paradigmas da política ambiental dos Estados. Este tipo de progressos têm sido inclusivos ao desenvolvimento normativo desde os textos constitucionais até as disciplinas das ciências jurídicas para sua proteção, onde se estabelecem direitos ambientais, inclusivos da participação cidadã para alcançar o desenvolvimento sustentável. Executa-se uma análise dos instrumentos de proteção ambiental, ligados ao controle público do meio ambiente -avaliação do impacto ambiental, inspeção ambiental, licença ambiental e auditoria ambiental-. Por estas 158 
razões, o objetivo do artigo é sistematizar os elementos que configuram aos instrumentos de proteção ambiental (avaliação de impacto ambiental, inspeção ambiental, licença ambiental e auditoría ambiental) para delimitar seus pontos de conexão entre estes como parte da política ambiental para alcançar uma gestão ambiental adequado e sustentável.

Palavras-chave: gestão ambiental, proteção ambiental, instrumentos do mercado de caráter cooperativo.

\section{EXORDIO}

La cuestión social, generada por las dramáticas injusticias sociales provocadas por los excesos del liberalismo económico en los inicios de la Revolución Industrial en Europa y América (siglos XVIII y XIX), con jornadas de 14 y 15 horas de trabajo en fábricas y minas, salarios míseros, la explotación de menores y mujeres, enfermedades y muertes de trabajadores por la ausencia de normas de higiene y salubridad, es el origen del movimiento sindicalista y de la legislación laboral. La cuestión ambiental, o la toma de conciencia acerca de la gravísima crisis ecológica y ambiental -los fenómenos de contaminación, degradación y daños ambientales en los ámbitos planetario, hemisféricos, nacionales y locales- a partir de la década de los 70 del pasado siglo (Conferencia de Estocolmo, 1972) es el origen del movimiento ambientalista y de la legislación ambiental, y del Derecho Ambiental como transversalización axiológica.

La asunción de esta nueva responsabilidad estatal se lleva a cabo por medio de leyes y por las entidades públicas especiales, lo que ha traído como consecuencia la proliferación de normativas administrativas de contenido ambiental: leyes, reglamentos, ordenanzas locales, actos administrativos unilaterales, contratos, concesiones, etc. La disciplina jurídica que mayor influencia ha recibido de la cuestión ambiental es el Derecho Administrativo. Se manifiesta en la adaptación de categorías jurídicas tradicionales del Derecho Administrativo a la gestión pública de los bienes ambientales, como en la creación de nuevas categorías que responden a la especificidad de esa gestión. Es observable en instrumentos jurídicos de control de las actividades susceptibles de degradar el ambiente, como las autorizaciones, licencias, inspección, evaluación de impacto ambiental y la auditoría ambiental, entre otros, vinculadas en el desarrollo del artículo. Y que como categoría jurídicotécnica es poco conocida en los otros campos de actividad de la Administración Pública. 
El artículo tiene como objetivo sistematizar los elementos que configuran a los instrumentos de tutela ambiental (evaluación de impacto ambiental, inspección ambiental, licencia ambiental y auditoría ambiental), para delimitar sus puntos de conexión entre estos, como parte de la política ambiental en pos de alcanzar una adecuada gestión ambiental sostenible y sustentable. Para ello fueron utilizados los métodos de la investigación como el histórico-lógico, el de análisissíntesis, y el inductivo-deductivo.

\section{EL DERECHO AMBIENTAL Y LOS INSTRUMENTOS DE TUTELA AMBIENTAL}

La noción de ambiente ha existido en la mente del ser humano desde tiempos pretéritos, de modo consciente o inconsciente, el hombre ha tenido una relación simbiótica con su ambiente, pues su dependencia de los recursos naturales es indiscutible; sin embargo, esta relación, se ha ido complicando con el paso del tiempo. Como realidad física del medio ambiente, tiene sus antecedentes en la palabra inglesa environment, traducida como "los alrededores, gente, modo de vida, circunstancias, en que vive una persona."; la palabra alemana Umwelt, cuya traducción sería "el espacio vital natural que rodea a un ser vivo"; y la francesa environnement, que equivaldría en castellano a entorno. La religión occidental se asumió un punto de vista respecto a la relación entre el hombre y el medio natural, sintetizado en el Génesis, donde se afirma “(...) y los bendijo Dios diciéndoles: 'Procread y multiplicaos y henchid la tierra; sometedla y dominad sobre los peces del mar, sobre las aves del cielo y sobre los ganados. Y, sobre todo cuanto vive y se mueve sobre la tierra" (1-28).

En este contexto Geoffrey Sto Hilaire, incluye en 1835, el concepto de medio ambiente. Desde el punto de vista filosófico esta expresión se refiere al conjunto de relaciones entre el mundo natural y los seres vivientes, influyen en la vida y el comportamiento del ser vivo. Lorenzetti (1998), lleva al análisis de los derechos del hombre con el enfoque del paradigma; la declaración aprobada en 1949, donde el derecho a la protección del medio ambiente no fue aprobado en sus inicios, sino que ocurre en un tercer momento, a consecuencia de los nuevos avances tecnológicos que repercutían de manera negativa en la calidad de vida, el consumo, para proteger el patrimonio cultural e histórico, y la defensa del patrimonio genético. Llamados como derechos de cooperación y solidaridad desde la doctrina, delimitado en el derecho al medio ambiente. La primera referencia internacional que conectó de manera explícita los derechos humanos con el medio ambiente fue el Pacto Internacional de Derechos Económicos, Sociales y Culturales en Nueva York en 1966, en la década de los 70 se publicó el 
primer informe del Club de Roma, "Los límites del crecimiento" y se celebró posteriormente la Conferencia de Estocolmo sobre el Medio Ambiente Humano en $1972^{2}$.

Fernández Rubio-Legrá (1987), señalaba que en las últimas décadas del pasado siglo el Derecho Internacional ha contribuido al desarrollo del Derecho Ambiental estatal en todos los países. Esto ha llevado a incrementar la concientización de que los intereses de la humanidad deben constreñir los intereses de los Estados individuales. Además, otros actores diferentes a los Estados han llegado a ser esenciales en la gestión de los cambios ambientales globales. Estos desarrollos siguen influyendo a un cambio fundamental en el paradigma del Derecho Internacional, evolucionando el campo ambientalista internacional. Refiere este autor consultado que, para la gran mayoría de los autores, el surgimiento del Derecho Ambiental Internacional se produce a finales de la década de los 70 , sin dejar de reconocer la existencia en períodos anteriores de precedentes aislados de instrumentos internacionales con un objetivo o dimensión ambiental. Otros, son más precisos y reconocen como fecha de la aparición del Derecho Ambiental Internacional a partir de la Declaración de Estocolmo sobre el Medio Humano en 1972, donde para muchos especialistas, esta Declaración constituye la Carta Magna del Derecho Ambiental, de aquí su maridazgo con el Derecho Internacional. (Fernández, 1991) $)^{3}$

Martin Mateo (1991) refería que en el Derecho comparado Giannini catalogó en el año 1973, tres posibles versiones del concepto del medio ambiente en el ordenamiento jurídico italiano: el medio ambiente en cuanto conservación del paisaje, es decir, bellezas naturales, centros históricos, parques naturales, bosques. El medio ambiente en cuanto normativa relacionada con la defensa del suelo, del aire y del agua. Y el medio ambiente en cuanto objeto de la disciplina urbanística. En 1975, lo definió como el ámbito físico de diversas acciones humanas, en el cual subsisten sistemas de equilibrio que puede ser modificado, pero solo a costa de reconstruir otros sistemas. Incluye en su concepto jurídico el ambiente como conjunto de elementos naturales objeto de protección jurídica específica, concretando que dichos elementos deben ser bienes comunes, de titularidad común y de naturaleza dinámica: en definitiva, el agua, el aire, y el suelo, aunque su gestión o bien se reconduce a la

2 Ver: Lorenzetti, Ricardo, Teoría del Derecho Ambiental, Editorial Porrúa, México, 2008; Morello, Augusto, Los Derechos del Hombre de Tercera y Cuarta Generación, en Estudios de Derecho Procesal. Nuevas demandas. Nuevas respuestas, Editorial Platense, 1998, p.947; Laciar, Mirta, Medio Ambiente y Desarrollo Sustentable, Editorial Ciudad, Argentina, 2003, p.323; Alexy, Robert, Teoría de los derechos fundamentales, versión de Ernesto Garzón Valdés, Centro de Estudios Políticos y Constitucionales, Madrid, 2001, p.86. 3 Ver. Informe Comisión Mundial sobre el Medio Ambiente y el Desarrollo, conocido como Informe Brundtland "Nuestro Futuro Común", publicado por Alianza Editorial, Madrid, 1987, p. 460, presentado a las 
ordenación global del territorio, o bien se conecta con los ciclos del agua y el aire. La protección contra el ruido y otras agresiones físicas que utilizan el agua y el aire. (Martín, 1991)

Desde la Teoría General del Derecho(Abidin, sf), se refiere que la naturaleza jurídica del derecho que posee el individuo con respecto al medio ambiente, partiendo de la teoría del interés, la relación de un sujeto con un bien o una relación contemplada como accesible a aquél , y evaluada como idónea para colmar una carencia o justificar una exigencia, o en parecidos términos, la relación entre un sujeto, al que se refiere una necesidad, y el bien idóneo para satisfacer tal necesidad, determinada en la previsión general y abstracta de una norma, podríamos pensar que el derecho al medio ambiente es un Interés Público en el sentido de directo y legítimo de la colectividad (Abidin, s.f). Esta teoría está guiada por una diferenciación entre Derecho Público y Derecho Privado, con la consecuencia que el primero sólo protege derechos subjetivos, mientras que el segundo, además de derechos subjetivos, protege los llamados intereses legítimos.

Aplicado al Derecho Ambiental, vería en el derecho al medio ambiente un interés público, con relevancia decantada hacia el bien común, hacia el uso de los bienes conforme a la función pública, pero sin que tuviese relevancia alguna el interés individual, más que cuando hubiese un ataque personalizado a la propiedad, salud, intimidad o actividad industrial de algún individuo. El matiz público del Derecho Ambiental no lo da el sujeto interviniente como la actividad desempeñada, la situación jurídica individualizada creada como consecuencia de poner el interés individual de la persona en contacto, directa o indirectamente con los bienes objeto del Derecho Ambiental.

Jaquenod De Zsögön (1991) señalaba que el medio ambiente supone la sistematización de diferentes valores, fenómenos y procesos naturales, sociales y culturales, que condicionan en un espacio y momentos determinados, la vida y el desarrollo de los organismos y el estado de los elementos inertes, en una conjunción integradora, sistemática y dialéctica de relaciones de intercambio entre el hombre y los diferentes recursos (p. 372).

Jordano Fraga (2007) considera que el Derecho Ambiental es una disciplina autónoma, que tiene requisitos como: presencia de principios propios, técnicas jurídicas propias y referencia a determinada categoría de personas, de objetos o de relaciones. ${ }^{4}$

4 Ver: BOTASSI, Carlos, (1997) Derecho Administrativo Ambiental, Editorial Platense, Argentina, p. 92. 162 
Retomando a Martin Mateo (1998), quien defendiera la idea de que el Derecho Ambiental se caracteriza por sustratum ecológico, especialidad singular, énfasis preventivo, componente técnico-reglado, vocación redistributiva, primacía de los intereses colectivos, multidisciplinar, mixtura normativa de lo antiguo y de lo nuevo, transnacional. Es un Derecho interdisciplinario, multidisciplinario calificado por su finalidad de orden público, interés público y utilidad pública, el Derecho Ambiental es un derecho reactivo, del riesgo y de la seguridad.

El Derecho Ambiental, como disciplina autónoma, reguladora de determinados derechos y obligaciones de las personas, se origina mediante la utilización, transformación o explotación de una serie de bienes que cumplen, a modo de límite del Derecho de la Propiedad, la función social de preservar el equilibrio entre el desarrollo económico y la calidad de vida. La función social que cumple tiene enorme complejidad, a cada momento social se deberá dar por el legislador relevancia a aspectos con más trascendencia pública que privada, o a la inversa, nuestra disciplina está en continua evolución, al tener por objeto uno de los ámbitos donde el derecho va siempre a remolque: La salud de la persona, su calidad de vida en equilibrio con la económica.

Dentro de este los instrumentos de tutela ambiental en sus clasificaciones tienen un concepto amplio de lo que son, y tienden a describir todos los aspectos del Derecho Ambiental que han sido reseñados. Entrarían por consiguiente medios políticos, jurídicos, técnicos, económicos, sociales y culturales. Podían tener interés en los momentos iniciales del Derecho Ambiental en los que, precisamente, se habían tomado a préstamos las tradicionales instituciones administrativas de policía, y fomento. Pero en el actual desarrollo del Derecho Ambiental es una perspectiva clasificatoria no pertinente. Sin embargo, sí es conveniente precisar que muchos instrumentos dependen de decisiones políticas fundamentales sobre opciones con muy radical repercusión en el modelo ambiental a establecerse. Entre ellas resaltan la elección estatal de entre las diferentes fuentes de energía, relacionadas con los principios del Derecho Ambiental. Entre estos: Protección espacial (planificación, ordenación del territorio, espacios protegidos); Evaluación de impacto ambiental; Instrumentos económicos; Participación ciudadana.

Estos elementos han conllevado a la necesidad de reestructurar las instituciones clásicas del Derecho Administrativo e inducir de la realidad de la cuestión ambiental nuevas categorías para actualizar y reformar la Teoría general del Derecho Administrativo, a tal magnitud ha 
llegado el impacto de las nuevas realidades sociales y económicas del fenómeno. Y, desde esa inquietud, analiza los instrumentos de tutela bajo los conceptos generales de acción administrativa imperativa, estimulante, consensual, compensatoria, orientada hacia el riesgo y abierta a revisiones y fundamentadora de la innovación. Hoy apreciadas con la responsabilidad ambiental compartida, al decir de autores como Manuela Mora (2012), Embid Irujo, Sanz Rubiales (2012), y Sanz Larruga. $^{5}$

\section{LAS HERRAMIENTAS DE GESTIÓN, ORIGEN Y EVOLUCIÓN}

Sus orígenes y evolución se constatan a partir del reconocimiento por los Estados de los Estados de los problemas ambientales. En su proceso de evolución ha avanzado superando tres etapas, de lo que ha sido la concientización ambiental, acontecida en la segunda guerra mundial; en los años 60 y 70 del pasado siglo XX, aparecen políticas ambientales acompañadas del desarrollo de la ecología y la aparición de interpretaciones multidisciplinarias, en los intentos de asociar las ciencias del hombre y las de la naturaleza. Una última etapa se aprecia a partir de la Cumbre de Rio de Janeiro en la década de los 90, al despertar la alarma mundial derivada de la crisis ambiental. Dicho de otra manera, los problemas ecológicos dejaron de ser analizados en prácticas de laboratorio, pasando a ocupar espacios noticiosos en los medios de comunicación internacionales, marcando como otro hito la firma de la Convención de la Biodiversidad (preservación de la vida) (Walsh, 2000, p. 1-63).

Como consecuencia de lo señalado, se reconoce una fuerte intervención estatal en los asuntos relacionados con la protección ambiental, a los que se les ha denominado: las normas de comando y control, y los instrumentos económicos. Bajo la teoría del comando y control, fundamentada en los estándares fijados por la Autoridad Ambiental, se acompañan de regulaciones para que estos estándares establecidos en los cuerpos jurídicos sean cumplidos por las personas naturales y jurídicas. Aquí se reconocen los instrumentos de mercado como mecanismos de control directo, con el objetivo de incentivar actividades sostenibles y procesos limpios, que permitan la introducción de los resultados de la ciencia y la técnica, y la aplicación de herramientas del tipo económico (impuestos, tasas, permisos negociables, incentivos, subvenciones, multas).

5 Ver: MORA RUIZ, Manuela, Tendencias del Derecho Administrativo. El Derecho Administrativo Ambiental: transformaciones en el Derecho Administrativo general en, Revista Derecho y Conocimiento, España, 2012; SANZ RUBIALES, Iñigo, El mercado de los derechos a contaminar, Editorial Lex Nova, España, 2012. 


\subsection{La Inspección Ambiental}

Deviene en una técnica de intervención sobre la actividad administrativa de creciente utilidad. Su presencia ha desbordado los tradicionales ámbitos de actividades de gestión financiera, prestacionales de sanidad, higiene y educación, para ganar presencia en sectores más emergentes como la economía (pesca, agricultura) y la industria, los servicios de interés general (recursos hídricos, electricidad y energía, telecomunicaciones, transporte), consumo, medio ambiente y urbanismo. A ello, debe sumarse el hecho de que su contenido vincula a las más importantes instituciones del Derecho Administrativo, desde la actividad administrativa propiamente, pasando por organización y función pública, hasta procedimientos y actos administrativos, potestad sancionadora, control administrativo, responsabilidad, entre otros.

Pero ello no indica que la inspección contenga una categoría jurídica de novedosa introducción en el Derecho Administrativo, todo lo contrario, su arraigo en la práctica de las Administraciones es en buena medida, consustancial al propio desarrollo de esta Ciencia. Conjuntamente, en materia de regulación jurídica se asiste a una dispersión normativa ocasionada por una creciente reglamentación sectorial en término muchas veces no compatibles, que se agudiza con la carencia de una regulación general sistematizadora de sus elementos (Rebollo Puig, 2004, p. 449). Tal referente se aprecia inclusive en los pronunciamientos de los máximos intérpretes y controladores de la Convencionalidad, Constitucionalidad y legalidad.

Como bien sostiene Rebollo Puig (2004), desde la realidad Española, pero aplicable a disímiles contextos:

Una regulación de la inspección administrativa es especialmente necesaria por la elemental razón de que aquí el ámbito cubierto por la actuación administrativa sancionadora es más amplio que en otros países y que, en consecuencia, donde en éstos basta una regulación de la investigación judicial de los delitos, entre nosotros es muchísimo lo que depende de la inspección administrativa de las infracciones. (p. 449)

Conviene por ello valorar los elementos de las más importantes posiciones teóricas sostenidas al respecto. En tal sentido, un primer grupo identifica la inspección como actividad, con referencias a los vínculos de la actividad sancionadora y la de control preventivo o represivo. En esta vertiente destacan los criterios de Sánchez Morón, para quien la inspección es: 
"Una actividad formalizada que tiene por finalidad verificar, igualmente con carácter preventivo o represivo, el cumplimiento de deberes u obligaciones, prohibiciones o limitaciones impuestas por la legislación vigente." Aquí destacan los elementos de la formalización de la actividad, su carácter preventivo o represivo y la comprobación del cumplimiento de la legalidad, sea cual sea la intervención. (p. 660)

Siguiendo esa línea, García Ureta (2006) la califica como:

(...) una actividad administrativa ordinaria de intervención, de carácter ejecutivo para la comprobación del ejercicio de derechos y obligaciones por parte de un particular, con el fin de determinar su adecuación al ordenamiento jurídico. Esta actividad incluye la recopilación de datos, la vigilancia, la investigación y, en especial, la verificación del desarrollo ordenado de la actividad de la que el particular sea titular. (p. 29)

Esta construcción para, como las anteriores del criterio de los derechos y obligaciones impuestos por la legalidad al particular, destacando los elementos de las fases de los procedimientos administrativos, y su carácter ejecutivo por encima del formal señalado por Sánchez Morón, con la cualificación del cumplimiento del principio de legalidad como adaptación al ordenamiento jurídico. Un segundo grupo, suele encuadrarla como mecanismo de control posterior puramente. Así, pueden ser identificados los criterios de Bermejo Vera (1998), quien fundamenta que:

Se habla de actividad, función o potestad de inspección, sin excesiva precisión en este momento, para identificar unas actuaciones, más o menos genéricamente previstas en el ordenamiento jurídico, que habilitan a las Administraciones públicas para llevar acabo funciones de comprobación o constatación del cumplimiento de la normativa vigente, en su sentido más amplio, esto es, incluidas muy especialmente las condiciones y requisitos de orden técnico, consecuencia inherente de la imposición que a determinadas personas, actividades, instalaciones, objetos y productos hacen ciertas normas jurídicas. El motivo principal de la dotación y ejercicio de estas funciones de inspección y control es, en cualquier plano, la seguridad. (p 40-41) 
Esta resulta una de las definiciones más acabadas en la doctrina, que introduce un aspecto importante: las múltiples miradas de la inspección como potestad, actividad o función, aspecto que ha tomado diversos caminos. En igual sentido, la caracterización técnica de la actividad inspectora se conjuga con la legalidad para configurarse como un control de legalidad técnica.

En tercer lugar, se distingue una posición que la asocia como actividad auxiliar a otras. Desde esa línea, Rebollo Puig (2009), señala:

La inspección es una actividad administrativa auxiliar de otras porque siempre tiene por finalidad detectar hechos que deben dar origen al ejercicio de otras potestades administrativas: no sólo la sancionadora, como simplistamente puede pensarse, sino a otras muchas de intervención de entidades de crédito, de reintegro de subvenciones, de restablecimiento de la legalidad, etc. Aun así, ella misma cumple por sí sola una función de prevención general que refuerza la observancia de los deberes. Y, en cualquier caso, aunque auxiliar de otras, se presenta formalmente al margen de esas otras. (p. 55)

De tales posiciones analizadas, emanan algunas características relevantes que precisan ser sistematizadas:

1) La inspección administrativa ha sido vislumbrada desde una óptica tripartita, bien como potestad reconocida en el ordenamiento jurídico a la Administración Pública, bien como función pública desarrollada por inspectores (funcionarios), bien como técnica de intervención de actividad material de control o policía, que no resultan incompatibles, sino resultan diversas posiciones jurídicas del ciclo de la actividad inspectora (ente administrativo atribuido de potestades exorbitantes en régimen reglado, funcionario público habilitado competencialmente y actividad investigativa de hechos, documentación de información y comprobación). Como potestad puede ser entendida como una técnica de atribución de poder, propia de la teoría general del Derecho y expresión del principio de legalidad (juridicidad), que emana directamente del ordenamiento jurídico, para el reconocimiento de una situación de poder de incidencia de los órganos de inspección hacia una actividad o sector de la actividad administrativa o particular, con el objetivo de producir efectos jurídicos derivados de la comprobación de la actividad con los criterios técnico legales, sin que ello genere de facto relaciones 
jurídicas, derechos o deberes; sino una sujeción al ordenamiento jurídico, a partir de posiciones pasivas.

Como parte del criterio función del Derecho Administrativo, matizado por la arista subjetiva de la organización administrativa, se entiende como la acción administrativa desplegada por un funcionario (inspector), inserto en el tejido administrativo de forma estable, bajo las formas de ingreso y permanencia establecidas legamente para el cuerpo de inspección, que en ejercicio de las competencias profesionales aparejadas a su formación, eficacia y experiencia, realiza con objetividad y proporcionalidad un análisis de conformidad de las manifestaciones de la actividad inspeccionada con los requerimientos establecidos en normas generales y reglamentarias de carácter técnico que ordenen el desarrollo de la actividad ${ }^{7}$. Como técnica de intervención de actividad material de control, tiene como fin la aludida verificación de cumplimiento de la actividad inspeccionada con el contenido de deberes $\mathrm{u}$ obligaciones, prohibiciones y limitaciones reconocidas desde el orden legal o reglamentario para el desarrollo de la actividad, bien con carácter preventivo o posterior.

2) Es de naturaleza individual, no depende ni requiere de la voluntad o del concierto del administrado ni de otros sujetos (en principio) para su plena eficacia y puesta en ejecución, incluso en aquellos casos en los que el título habilitante para el ejercicio de la potestad inspectora provenga $o$ esté conectado con la participación voluntaria del administrado en una determinada relación jurídica de naturaleza administrativa (relación contractual de servicios públicos).

6 Se sigue en este sentido el criterio de la doctrina italiana sistematizado por GARCÍA DE ENTERRÍA y RODRIGUEZ FERNÁNDEZ y extendido a parte importante de la doctrina española, GARCÍA DE ENTERRÍA, Eduardo y FERNÁNDEZ RODRÍGUEZ, Tomás, “Curso de Derecho Administrativo ”, Tomo I, $15^{\text {ta }}$ Edición, Editorial Thompson- Cívitas, Madrid, 2011, p. 466 y ss., ZANOBINI, Guido, Curso de Derecho Administrativo, Volumen I, Parte General, traducción de la $5^{\text {ta }}$ edición italiana (1949) por Héctor MASNATTA y actualizada con la $6^{\text {ta }}$ edición por Francisco PICONE, Ediciones ARAYÚ, Buenos Aires, 1954, p 227 y ss., GIANNINI, Massimo Severo, "Derecho Administrativo", Editorial INAP, trad. Pos. ORTEGA, Luis, Volumen Primero, Madrid, 1991, p.171 y ss, BACIGALUPO SEGGESE, Mariano, "Las potestades Administrativas", en CANO CAMPOS, Tomás, Lecciones y Materiales para el Estudio del Derecho Administrativo. Tomo III. La Actividad de Las Administraciones Públicas. Volumen I. La forma, $1^{\text {ra }}$ Edición, Editorial Iustel, Madrid, 2009, LINDE PANIAGUA, Enrique, "Fundamentos de Derecho Admimstrativo. Del Derecho del poder al Derecho de los ciudadanos", $2^{\mathrm{da}}$ Edición, Editorial UNED, Madrid, 2010, p. 267 y ss, GAMERO CASADO, Eduardo y FERNÁNDEZ RAMOS, Severiano, Manual Básico de Derecho Administrativo. $7^{\mathrm{ma}}$ edición, Editorial Tecnos, Madrid, 2010, pp. 58-59.

7 En este sentido se siguen los criterios básicos de la función administrativa establecidos por CASSESE, Sabino, "Las Bases del Derecho Administrativo", trad. pos., Luis ORTEGA, Editorial INAP, Madrid, España, 1994, pp. 106-116; SANTAMARÍA PASTOR, Juan Alfonso, "Principios de Derecho Administrativo General", $2^{\text {da }}$ edición, Editorial Iustel, España, 2009, p.641 y ss; PAREJO ALFONSO, Luciano, "Lecciones de Derecho Administrativo", $3{ }^{\text {ra }}$ edición revisada y actualizada, Editorial Tirant lo Blanch, Valencia, p.755 y ss.; PARADA, Ramón, "Derecho Administrativo. Organización y empleo público", Decimosexta Edición, Editorial Marcial Pons, 2003, Madrid, p. 381 y ss.; BLANQUER, David, Curso de Derecho Administrativo I. Los sujetos y la actividad, Editorial Tirant Lo Blanch, Valencia, 2006, pp. 358-359. 
3) En relación al ámbito de inspección, la actividad puede desarrollarse hacia lo interno de la organización administrativa, como hacia lo externo, en la actividad de otras Administraciones o particulares (Rebollo, 2009, p. 57).

4) Resulta una actividad de comprobación de legalidad (juridicidad) en la actividad de los particulares conforme a las reglas establecidas, bien desde disposiciones generales habilitadas con preferencia mediante Reserva de Ley, bien desde normas reglamentarias para el desarrollo de la actividad inspeccionada (Blanquer, 2007, p. 162).

5) Sus efectos tienen un carácter instrumental al ejercicio de otras potestades administrativas como la sancionadora o la procedimental, en una actividad en concreto desarrollada por la Administración, con independencia de la fórmula de gestión, lo mismo en el procedimiento autorizatorio, tributario o sancionador, inmobiliario, o de otra administración sectorial. Sin embargo, debemos afirmar que posee una autonomía propia que las diferencia de aquellas como mera fase o instrumento, pues obedece a fines y funciones propias que, aunque coadyuvan a aquellas, desbordan el contenido de aquellas, pues en reiterados casos se desarrolla para obtener una actualización del estado de funcionamiento de la actividad inspeccionada y en consecuencia planificar una actividad tendente a la mejor progresiva de la calidad y eficiencia del servicio. De ahí que la potestad de inspección tenga como fin la comprobación de la certeza de juridicidad; expresando el resultado de la intervención de control, mediante evidencia documental certificante del estado de compatibilidad de la actividad administrativa con sus parámetros de ordenación (Blanquer, 2007, p. 360).

6) Es una función de carácter técnico. El ejercicio de la función requiere un alto nivel de cualificación y habilitación técnica para el desempeño, de ahí que su desarrollo atienda a factores como la competencia, formación del inspector, conocimientos y aptitudes demostradas en la actividad. Ha sido precisamente ese carácter tecnocrático, el que ha influenciado en los años recientes la externalización en el desarrollo de esta actividad desde formas de gestión indirecta, a partir de mecanismos de colaboración público-privada (Fernández, 2002).

7) Es una potestad de ejercicio reglado, no cabe discrecionalidad en su aplicación. Debe de ajustarse a un canon de objetividad, eficiencia, transparencia y responsabilidad, que permitan asegurar, desde la planificación y control de su ejercicio, la debida neutralidad, probidad y cumplimiento estricto de la juridicidad por parte del inspector (Blanquer, 2007, p. 362). 
8) Tiene un efecto fedatario sobre la actividad inspeccionada. Esta facultad reconocida a los notarios públicos, se desarrollada en la inspección mediante las Actas de inspección, verdaderos informes que certifican el estado de compatibilidad de la práctica administrativa en relación con la ordenación jurídica de la actividad, a las que el ordenamiento procesal les atribuye el carácter vinculante y directo en la fase probatoria, por la certeza y veracidad que la competencia del inspector aporta en el Acta Blanquer, 2007, p. 359).

9) En algunos supuestos, sobre todo en casos de gestión indirecta, pueden resultar una actividad de carácter oneroso para la inspeccionado, porque así lo requiera para la certificación de hechos o circunstancias relativas a su actividad o por un tercero con interés procesal o técnico, creado en virtud de una relación orgánica. A ello se agrega la posible preferencia de un cuerpo de inspectores ajenos a la actividad inspeccionada que brinde un mayor nivel de neutralidad en las valoraciones técnicas emitidas en el Acta (Blanquer, 2007, 361).

Sentadas las características, resultaría conveniente referirnos a los principios que informan la actividad inspectora. En primer lugar, el principio de legalidad (juridicidad) deviene en eje estructural de esta potestad, pues la comprobación de conformidad se realiza desde los criterios técnicos establecidos para la actividad inspeccionada. Su desarrollo, atendido a los criterios reglamentarios y legales, impone por un lado una verificación de lo normado en el desarrollo de la actividad inspeccionada, y por otro, una función inspectora acorde al canon de legalidad, de vinculación positiva, mediante el cual se asegura la sujeción de la actividad a la norma jurídica administrativa. De igual forma, debe destacarse uno de los principios de mayor invocación en el Derecho Público, el de proporcionalidad. Según la aplicación de este principio, y siguiendo a Rivero, deben de establecerse un justo balance de ponderación entre la calidad e intensidad de la función inspectora en relación a la eficiencia de la actividad inspeccionada, de modo tal que esta no resulte inoperativa o en estado de inactividad como consecuencia de la intervención de la función inspectora (p. 162).

En igual sentido, vinculado al ámbito subjetivo de la función inspectora, el principio de objetividad o imparcialidad, impone una actitud y desempeño inmaculado del inspector, ajeno a favoritismos, parcializaciones de índole políticas, administrativas o motivadas por dádivas económicas monetarias o en especie. La función inspectora debe ser desarrollada de modo independiente, incluso, sin predisposiciones o indicaciones de superiores jerárquicos de fuerzas políticas o 
administrativas externas. En resumen, debe de deberse solo al estricto deber de comprobación de compatibilidad de la legalidad con la actividad inspeccionada.

Por último, nos referimos al principio de confidencialidad de la información obtenida y deber de secreto y discreción de los inspectores. Bajo la égida de este principio de actuación de la función inspectora, se destaca una de las exigencias fundamentales para los funcionarios que desarrollan la actividad, la del manejo adecuado y exclusivo de la información obtenida conforme a los resultados de la inspección. Así ha de exigirse que esta no sea manejada con terceros ajenos a la relación de inspección o con los beneficiarios directos de sus resultados, caso en contrario podrían generarse lesiones incidentales directas a la actividad inspeccionada e imputable a la inspección por la violación de algún derecho reconocido a personas naturales o jurídicas.

Pero no basta la ordenación de principios rectores de la actividad, resulta preciso para su desarrollo una adecuada ordenación de las facultades derivadas de la potestad de inspección. Siguiendo a Muñoz Machado, entre las normas sectoriales, como tendencia, son reconocidas las potestades de:

Requerir información, la exhibición de documentos, la comparecencia de los inspeccionados ante las oficinas públicas, la facultad de entrada en fincas, instalaciones o recintos de propiedad particular, la toma y análisis de muestras, las visitas de inspección, etc. Inclusive se prevé la facultad de requerir aquellos datos necesarios para las finalidades de la inspección que sobre un sujeto puedan estar en poder de terceros o de otras Administraciones públicas."

Pero estas potestades deben ser ejecutadas desde un prisma de proporcionalidad, de modo tal que no afecten de modo irrazonable el ejercicio y disfrute de derechos fundamentales de los inspeccionados, como por ejemplo el derecho a la intimidad, que, al decir de Rivero Ortega:

Es el derecho que más seriamente puede verse afectado por técnicas consistentes sobre todo en la recopilación de datos e informaciones. Pero también la igualdad, no siendo aceptable la focalización de las intervenciones inspectoras en sujeto determinado, de forma arbitraria o discriminatoria. (p. 162) 
Pero no agota su posible incidencia negativa en el derecho a la intimidad, sino que puede generar estados lesivos a los derechos desde el resultado de la actuación como la inviolabilidad del domicilio, del secreto de las comunicaciones, o la protección de los datos de carácter personal. Por otro lado, puede generar fricciones con los derechos de toda persona a no declarar contra sí mismo y del derecho a obtener información sobre sus derechos, cuestión de la que data una doctrina jurisprudencial importante.

Se valora como la inspección constituye una actividad material de la Administración, esta tiene lugar a través de un despliegue de medios personales y materiales para realizar las comprobaciones que correspondan. Es una actividad técnica, realizada por funcionarios públicos cualificados y bajo ciertos procedimientos y estándares de actuación. Constituye en sí misma un acto trámite, dado que su realización sirve a decisiones administrativas ulteriores. Es una auténtica potestad de la Administración. Su titularidad es completamente pública. Como técnica de intervención administrativa, responde al mecanismo o medio que se emplea para lograr determinados fines. Es una actividad esencialmente instrumental. La particularidad de la inspección radica en que resulta ser una técnica doblemente instrumental, al servicio de la eficacia del ordenamiento jurídico y de ciertos actos administrativos (su finalidad inmediata) y al servicio de la protección de los intereses generales de la comunidad (su finalidad mediata).

El ejercicio concreto de la potestad de inspección implica la formación de una relación jurídica entre la Administración y el ciudadano. La relación jurídica de inspección es aquella que se da entre un órgano de la Administración que tenga atribuido el ejercicio de dicha potestad y un particular que se relaciona de alguna manera con el objeto de la inspección. El sujeto activo de la relación jurídica de inspección corresponde a un órgano de la Administración del Estado que ostente potestad para ejercer funciones inspectivas o fiscalizadoras.

Al ser la inspección una función pública, su ejercicio debe quedar reservado, en primer lugar, a los funcionarios públicos. Con todo, las crecientes necesidades experimentadas por la Administración en el control de la técnica y sus riesgos han planteado nuevos dilemas en torno a la forma de organización de la inspección y a los recursos con que cuenta para ser ejecutada eficazmente.

Los inspectores pueden llegar a tener un conocimiento elevado respecto de la aplicación y cumplimiento de las normas jurídicas y de los actos 
administrativos que regulan a un determinado sector. Son portadores de información valiosa para la configuración de nuevas modalidades, planes o programas de inspección, que tengan en consideración las particularidades propias de la realidad frente a la cual ellos se enfrentan en el ejercicio de sus funciones.

Se aprecia cómo el principio de prevención no sólo está asociado a la inspección como técnica de intervención, sino que, en general, resulta predicable de innumerables otras técnicas relacionadas con la ordenación de diversas actividades económicas y sociales. Es un principio general que rige la actividad de la Administración. Con la inspección, primordialmente, se pretende evitar o rechazar los peligros que pudieran afectar al orden público. Así, el tradicional binomio ordenación-sanción contempla un nuevo matiz- intermedio, si se quiere protagonizado por la prevención. En este sentido, la inspección es útil por dos razones: Primero, porque otorga una herramienta - el conocimiento al legislador y a la Administración para el diseño de nuevos mecanismos que eviten la producción de daños en el actual contexto de la sociedad del riesgo; segundo, porque produce un efecto intimidatorio sobre los ciudadanos que no son sujetos directos de ella, pero que sí pueden serlo en un futuro próximo. La inspección es, como advierten algunos, "una advertencia de control permanente del cumplimiento de obligaciones y deberes".

Sus dos funciones primordiales se constatan a través de la comprobación o verificación y la tutela de los intereses generales. En la doctrina más actual, se ha caracterizado a la potestad de inspección como una actividad unilateral desarrollada por la Administración para la comprobación del ejercicio de derechos y obligaciones por parte de un particular, con el fin de determinar su adecuación al ordenamiento jurídico. Incluye la recopilación de datos, la vigilancia, la investigación $y$, en especial, la verificación del desarrollo ordenado de la actividad que el particular sea titular.

La potestad de inspección es una forma de intervención administrativa, unilateral, de carácter material e interlocutoria de decisiones administrativas ulteriores, realizada con la finalidad de comprobar la adecuación del ejercicio de derechos y obligaciones de los particulares al ordenamiento jurídico y a los actos administrativos que los rigen. Al ser una potestad pública, su atribución debe realizarse por ley. Sus características son la atribución que hace la ley de una potestad a la Administración, la que puede ser reglada o discrecional, la potestad fiduciaria o potestad-función, esto es, que debe ejercerse en función de 
un interés distinto al de su titular, la potestad preventiva y correctora y la potestad autónoma de la potestad sancionadora.

Son sujetos pasivos de la relación jurídica de inspección todas las personas naturales o jurídicas que resulten obligadas al cumplimiento de las normas y de los actos de la Administración que rigen a la actividad inspeccionada. El objeto de la relación jurídica de inspección puede consistir en cualquier actividad, objeto o entidad regulada por el Derecho, esto es, sometida al cumplimiento de ciertos requisitos o condiciones para su correcto ejercicio, ya sea que tales requisitos y condiciones estén establecidos en leyes, reglamentos o en los concretos títulos habilitantes con los cuales deba contar la actividad. El objeto de la inspección nunca recae directamente en personas, puesto que estas sólo son titulares o responsables de las actividades inspeccionadas. El prestar testimonio o declaración en torno al desarrollo de una actividad no las transforma en objeto mismo de la inspección.

Es frecuente que una misma actividad pueda ser objeto de inspecciones múltiples. Ello ocurre en las actividades agrícolas, turísticas, educacionales, recreativas, de transporte, entre otras, las cuales están sujetas a la actividad de inspección realizada por diversos órganos administrativos.

En el caso de la inspección ambiental, se han ideado mecanismos que coordinan la acción fiscalizadora de la Superintendencia del ramo y los organismos sectoriales, para que sus inspecciones no signifiquen una duplicación de funciones administrativas y no afecten el normal desarrollo de las actividades inspeccionada. Ya dando un criterio, en lo relacionado a la protección ambiental en esta actividad de control, Fernández Ramos (2002, p. 21-29), considera que la acción inspectora en materia ambiental, como en cualquier otra materia, consiste en un aspecto de la actividad de ejecución de la legislación ambiental, tiene por objeto primordial la protección de la legalidad, mediante la vigilancia y fiscalización de su cumplimiento por parte de los sujetos obligados.

Se trata, por tanto, de una competencia de disciplina o policía administrativa. Y, debido a esta naturaleza ejecutiva, es claro que la actividad inspectora en materia ambiental se dirige a la protección del medio ambiente. El Estado se reserva competencias inspectoras en determinados ámbitos, como los traslados de residuos, en materia de vertidos al dominio público hidráulico en cuencas, o en materia de vertidos al dominio público marítimo-terrestre. 
Continúa este autor citando que debe tenerse presente que, al margen de la inspección ambiental propiamente dicha, derivada del título competencial sobre protección ambiental, dado que el medio ambiente no es un sector propiamente dicho sino un bien jurídico a tutelar e integrar en cualesquiera de los sectores productivos y de servicios, otras inspecciones sectoriales tienen entre sus fines institucionales el de protección del medio ambiente. Entre ellas: la inspección en materia de seguridad industrial, la cual tiene por objeto no sólo la protección de la seguridad y salud públicas, sino también de la fauna y flora y el medio ambiente en general de industria; la inspección en materia de marina mercante, que tiene por objeto garantizar tanto la normativa de seguridad marítima, como la prevención de la contaminación del medio ambiente marino producida desde los buques de inspección y certificación de buques civiles y la inspección en materia de pesca marítima, entre cuyos fines se encuentra evitar la sobreexplotación de los caladeros, como recursos naturales que son.

La inspección ambiental es un procedimiento metodológico que involucra análisis, pruebas y confirmación de procedimientos y prácticas de seguimiento que llevan a determinar la situación ambiental en que se encuentra un proyecto, obra o actividad y a la verificación del grado de cumplimiento de la legislación ambiental vigente. Es una evaluación objetiva de los elementos de un sistema que determina si son adecuados y efectivos para proteger al ambiente.

Esta inspección valora y controla si el funcionamiento y sistema de la empresa cumple con la normativa relacionada al medio ambiente como así también si es efectivo o no lo es, brindando en caso negativo las medidas correctivas o preventivas para la adecuación o ajuste de su sistema. Por lo tanto, el control y la fiscalización ambiental de las actividades productivas, es una herramienta de vital importancia para todos los actos de la administración, garantizando la correcta aplicación de la normativa legal y obligando al regulado a la implementación de medidas correctivas o preventivas cuando resulte necesario.

\subsection{La Evaluación de Impacto Ambiental}

Introducida por la National Environmental Policy Act de 1969, en los Estados Unidos de América. Esta norma es una de las pioneras en el mundo del Derecho ambiental moderno creó la Environmental Protection Agency, y codificó por primera vez principios del Derecho y política ambiental como la solidaridad intergeneracional o el reciclaje. Sin duda, la mayor innovación fue la Evaluación de Impacto Ambiental 
pretendiendo introducir, nada más y nada menos, la racionalidad ambiental en el proceso de toma de decisiones mediante una cláusula abierta.

Son procedimientos de evaluación de riesgos y en particular de estudios de "impacto ambiental" (Declaración de Río, principio 17) que incluye: Comunicación al órgano ambiental de la intención de realizar el proyecto, Consultas previas, Redacción del estudio de impacto ambiental, Información pública del estudio y la Declaración de impacto ambiental; el Estudio de Impacto Ambiental (EIA) como categoría jurídico-técnica, es aún desconocida en los otros campos de actividad de la Administración Pública, es un instrumento especial creado para la toma de decisiones en los procedimientos autorizatorios de actividades susceptibles de degradar el medio ambiente. Dicho estudio tiene, como objetivos, evaluar si los efectos degradantes de la actividad propuesta son "tolerables", es decir, que puedan ser objeto de control, mitigación, restauración y reparación. Es un medio de articulación de los principios de prevención y del daño tolerable.

El estudio realizado y la evaluación que se haga de la ejecución de la actividad autorizada con base en el mismo, tiene como fines: predecir, analizar e interpretar los efectos ambientales potenciales de una propuesta en sus distintas fases; verificar el cumplimiento de las disposiciones ambientales; proponer las correspondientes medidas preventivas, mitigantes y correctivas a que hubiere lugar; y verificar si las predicciones de los impactos ambientales son válidas y las medidas efectivas para contrarrestar los daños. Está concebida dentro de la familia de los instrumentos de gestión ambiental, previsto y regulado en la mayoría de los ordenamientos jurídico-ambientales de los Estados de la comunidad internacional, y en tal carácter, forma parte del proceso de estandarización de la normativa ambiental o Derecho Ambiental estándar que se aplica.

Por ello, sus dos elementos esenciales son el estudio de impacto ambiental y la declaración de impacto ambiental. Su naturaleza jurídica es preventiva (protección del medio ambiente). Es un instrumento de gestión pública. Es ejecutado por profesionales que requieren un título habilitante para su consecución. Con las competencias requeridas por la alta complejidad técnica de los aspectos que se debaten en esta evaluación al sujeto inspeccionado, como un equipo pluridisciplinar.

8 LEOPOLDO E SILVA JUNIOR, Alcides, El Estudio del impacto Ambiental como instrumento de prevención del daño al medio ambiente, en Direito Ambiental em Evolucao, coordinación de PASSOS DE FREITAS, Vladimir, Editorial Juruá, 2002, p.33; ANDORNO, Roberto, El principio de precaución: un nuevo estándar jurídico para la Era Tecnológica, Editorial La Ley, Argentina, 2003. 
Está claro su carácter incidental, puesto que no es más que una parte, aunque de gran importancia, del procedimiento global de control previo, o sea, del expediente aprobatorio o autorizatorio, en cuyo seno (y sólo en él) cobra virtualidad.

Su realización es imprescindible, por lo que el procedimiento incidental tiene carácter esencial. Si llegara a prescindirse de la previa evaluación, la consecuencia sería la nulidad del acto decisorio. Sus efectos: como procedimiento administrativo, su finalidad es identificar, predecir e interpretar los impactos ambientales que un proyecto o actividad producirá en caso de ser ejecutado. Con la declaración se determina la conveniencia o no de realizar el proyecto y fija las condiciones que deben establecerse en orden a la adecuada protección del medio ambiente.

\subsection{La Licencia Ambiental}

Como autorización, es un acto administrativo complejo que se dicta dentro de un procedimiento administrativo de autorización, dado por el órgano competente en materia ambiental, que integra todas las autorizaciones ambientales existentes en distintos sectores del medio ambiente. Es un instrumento de gestión pública en el que convergen y se expresan con nitidez los dos aspectos que componen al Derecho Ambiental a las exigencias de la sociedad del riesgo. Es el título habilitante en virtud del cual se ordena y gestiona el ejercicio de derechos inmersos en el tráfico jurídico-privado concurrentes con intereses públicos ambientales, en el marco del ejercicio de actividades potencialmente contaminantes. El objeto de protección de la autorización ambiental y su ámbito de aplicación indican la alta complejidad técnica de los aspectos que se debaten en la EIA, y que luego son plasmados en forma de condiciones en el contenido de este título. Las respuestas a las exigencias ambientales, la determinación de los impactos y su grado de incidencia son aspectos cuyas respuestas las encontraremos en la ciencia, en el estado de desarrollo de la técnica, y no a intramuros del Derecho, como lo refiere Pereira Basanta (2011), Rey Santos (2007), Lozano Cutanda (2004), Nogueira López (1998), Parejo Alfonso (2013) y Mora Ruiz(2007).

La determinación de si se autoriza determinada obra o instalación, y luego, del condicionado de la licencia no nos la proporciona exclusivamente el Derecho; algunas respuestas se hallan en las ciencias exactas, y otras ni siquiera son conocidas por los científicos expertos, sino que permanecen aún en espacios donde prima la incertidumbre 
científica. Por estos motivos es que llamamos la atención sobre la posición que desempeña la autorización ambiental en las sociedades contemporáneas; es un título con el que se gestiona los peligros y riesgos tecnológicos que producen determinadas actividades humanas, pero que la sociedad está dispuesta a asumir por los beneficios que trae aparejado.

Recordemos que el enfoque sectorial en la lucha contra la contaminación ambiental se hace latente en la década de los 70 del pasado siglo, a partir del dictado de leyes nacionales que se dirigían a regular ámbitos ambientales concretos para solucionar los determinados problemas suscitados en precisos sectores, sin adoptar una visión global o general que brindara una solución adecuada que tuviese en cuenta las interrelaciones que se producen entre los distintos medios naturales. En el Derecho comparado ya citábamos que en los Estados Unidos se regularon leyes como la Clean Air Act de 1970, la Federal Water Pollution Control Act de 1972, y la Resource Conservation and Recovery Act de 1976, como manifestaciones claras de acciones estatales contra la contaminación ambiental, cuyas medidas se dirigían a los sectores concretos de la industria, tal y como le refieren Fernández Rubio-Legrá, Martin Mateo, y Sardone (2008).

La licencia ambiental refiere que el ejercicio de actividades potencialmente contaminantes no debe limitarse a prevenir, limitar o reducir los peligros conocidos, sino a determinar los más posible contornos de riesgos, es decir, aquellos posibles impactos que pueden producirse en escenarios donde no se alcance a determinar con exactitud el peligro objetivo porque no se opera con todo el conocimiento científico para arribar a su total comprensión, pero que existan riesgos, cuyos efectos no sean del todo conocidos por la ciencia.

Es un mecanismo de determinación y control del peligro, entendido éste como el impacto ambiental perfectamente determinable por el conocimiento científico en determinada materia; pero la autorización ambiental es también el título donde se verterán los riesgos que acarreará la actividad en cuestión, entendido como la probabilidad de producción de determinados impactos de imposible determinación por operar en escenarios donde prima la incertidumbre científica respecto a un asunto en particular.

La distinción entre peligros y riesgos puede ser comprendida a través de los recursos que ofrece Esteve Pardo (2003). Los riesgos son generados por el empleo de tecnologías de cuyo empleo desconocemos una porción de los efectos y consecuencias que pueden acarrear para la salud y vida humana; a diferencia del peligro que encuentra su origen en los 
fenómenos naturales. Las novedades del Derecho Ambiental en el seno de la autorización ambiental continúan. En ejecución del postulado de la prevención de la contaminación ambiental, el Derecho europeo ha impuesto como parte del contenido de la licencia el cálculo de valores límites de emisión de sustancias contaminantes para la instalación.

En el Derecho comparado en la Unión Europea, se aprecia como novedoso en la autorización de valores límites de emisión de sustancias contaminantes para un período de tiempo determinado, sino el método para su cálculo. Para el cálculo de las cuotas de emisión de sustancias contaminantes se emplea el sistema de determinación en base a la mejor tecnología disponible en el mercado. La cláusula de progreso tecnológico se erige entonces en otro de los elementos que coadyuva directamente a esculpir la implementación del principio de prevención en esta figura autorizatoria.

La autorización, es un tipo de acto administrativo que generalmente se materializa a través de la forma escrita, pero el documento oficial es únicamente el soporte que sustenta a una declaración administrativa unilateral con efectos jurídicos directos sobre sujetos determinados, constituye una declaración unilateral de la Administración que, en ejercicio de la función administrativa, produce efectos jurídicos directos sobre situaciones jurídicas concretas e individualizables. La introducción de moderna tecnología limpia no se establece como una obligación del titular de la instalación impuesta por la legislación ambiental.

El titular del proyecto o instalación no se encuentra en la obligación legal de introducir aquellos avances tecnológicos que vayan surgiendo en el mercado, y que se traduzcan en reducción, o en su caso, eliminación de las emisiones contaminantes que produce. Así, el contenido mínimo del permiso denominado autorización ambiental integrada viene constituido por los siguientes aspectos: prescripciones que garanticen la protección del suelo y de las aguas subterráneas; procedimientos y métodos que se vayan a emplear para la gestión de los residuos generados por la instalación, prescripciones que garanticen la minimización de la contaminación a larga distancia o transfronteriza, sistemas y procedimientos para el tratamiento y control de todo tipo de emisiones y residuos, especificando la metodología de medición, su frecuencia y procedimientos de evaluación, medidas relativas a las condiciones de explotación en los casos de puesta en marcha, fugas, fallos de funcionamiento, paradas temporales o cierre definitivo.

9 Ver: ESTEVE PARDO, José, De la policía administrativa a la gestión de riesgos, en Revista Española de Derecho Administrativo, no. 119, España, 2003; MARTÍN MATEO, Ramón, Derecho Público de la Economía, Editorial CEURA, Madrid, 1985. 
El control integrado de la contaminación descansa fundamentalmente en la autorización ambiental integrada, figura que sustituye y aglutina el conjunto disperso de autorizaciones de carácter ambiental exigibles hasta el momento. Así lo concerniente a: producción y gestión de residuos, incluidas las de incineración y vertidos de residuos, vertidos a las aguas continentales, incluidos los vertidos al sistema de saneamiento, vertidos desde tierra a mar y contaminación atmosférica. De igual forma podemos apreciar que el procedimiento de la autorización ambiental integrada está guiado por dos parámetros: integración y publicidad. Esta perspectiva integradora, se convierte en una garantía que supone, indirectamente, una aplicación del Derecho Ambiental con carácter transversal. Ello en el sentido de que la autorización ambiental tiene carácter condicionante. Pero, además, la figura de la autorización ambiental integrada ha venido a refrendar un decidido propósito por incidir en una protección del medio ambiente "en la fuente" (Mora, 2007).

La autorización ambiental integrada no presenta, en principio, una naturaleza singular, puede encuadrarse dentro de las fórmulas de intervención administrativa de carácter imperativo o de policía, conocidas por la legislación en materia de contaminación, y concretamente, dentro de las autorizaciones sobre fuentes puntuales, en este caso instalaciones industriales, como mecanismo de control del cumplimiento de determinados estándares o niveles de emisión, teniendo en cuenta que lo subyace siempre a una autorización de esta naturaleza es la existencia de una regulación material. La originalidad de esta nueva normativa no radica, pues, en su naturaleza, sino en su finalidad o en sus objetivos (prevención y control integrados).

Se trata, de una normativa que pretende hacer realidad el principio de prevención de la contaminación en origen o de corrección de los atentados al medio ambiente, preferentemente en la fuente misma, mediante la exigencia del empleo de tecnologías limpias y no simplemente correctoras de la contaminación de un medio determinado (tecnologias end of pipe), susceptibles de provocar aquellas transferencias de contaminación, y propiciadas por el tradicional tratamiento sectorial de la contaminación industrial. Es aplicable a las instalaciones, de titularidad pública o privada. La solicitud deberá estar acompañada de la autorización gobernativa en materia de Derecho Urbanístico, acreditativo de la compatibilidad del proyecto con el planeamiento urbanístico.

La protección del Derecho Ambiental debe estar guiada por el cumplimiento de prioridades, efectivamente el desarrollo económico 
provoca que la sociedad deba asumir un riesgo que sea tolerable, pero al fin y al cabo es riesgo. Frente a la alternativa de reprimir, mediante la imposición de grandes multas y sanciones no se garantiza la protección del medio sino en todo caso su restauración. Por ello es necesario incidir en la fuente, en el origen. En suma, es necesario priorizar la aplicación del principio de prevención. ${ }^{10}$

\subsection{La auditoría ambiental}

Reconocida entre los instrumentos de mercado de carácter cooperador, como actividad de control en la llamada sostenibilidad o sustentabilidad -al margen de cualquier discusión etimológica- se ha convertido en el centro de las concepciones que sobre el desarrollo se han esgrimido desde el Informe Bruthland (1987). Institución jurídica, reconocida como herramienta de gestión en el Derecho Ambiental, se regula en normativas jurídicas especiales para su uniformidad, tiene un nexo causal: la exigencia de la responsabilidad ambiental y la cuantificación de los daños ambientales generados, la implementación de la responsabilidad social empresarial vinculada a la economía y la contabilidad ambiental. Elementos que han permitido que haya evolucionado con el transcurso del tiempo en relación con el país que la aplique y el desarrollo tecnológico industrial.

Su conexión, está relacionada a los orígenes del ius ambientalismo como parte de la Agenda Pública Internacional; las Entidades Fiscalizadoras Superiores señalan al año 1969 como su inicio, con posterioridad las cumbres ambientalistas han debatido los problemas ambientales del planeta y las medidas para su mitigación, han aportado al desarrollo de esta institución jurídica desde la doctrina del Derecho Público.

Textos en materia jurídica, de autores como Sardone (1988), revelan que se originó en los Estados Unidos de América a finales de los años 70 del siglo XX, apareció para evaluar al sector empresarial con la finalidad de servir como herramienta de dirección para la gestión ambiental ante el aumento y la complejidad de la normativa jurídica Estadual y Federal ante los problemas ambientales que acontecían en esta nación. ${ }^{11}$ En

10 Ver: LOZANO CUTANDA, Blanca, Tratado de Derecho Ambiental, Editorial CEF, España, 2015; JAQUENOD DE ZÖGÖN, Silvia, El Derecho Ambiental y sus principios rectores, Editorial Dikinson, España, 1991; FERNÁNDEZ DE GATTA SANCHEZ, Dionisio, "Principios del Derecho Ambiental, la responsabilidad social corporativa en materia ambiental” en, Boletín Económico ICE, número 2824, España, 2004; DEMALDÉ, Cristina, El principio de precaución en el daño ambiental, Universidad Nacional Autónoma de México, México D.F. 2011; CAFERRATA, Néstor, "Teoría de los principios del Derecho Ambiental' en, Revista Abeledo Perrot S.A., Argentina, 2009.

11 SARDONE, Andrea, "Valutazione di Impatto Ambientale in USA. Regulations N.E.P.A.", Editore Clup, Milano, 1988. 
respuesta a los problemas globales de contaminación, generados con la Revolución Industrial y los avances tecnológicos que trajo consigo en la década de los años 80 , se extendió la práctica de la auditoría ambiental a la Unión Europea como consecuencia de los intereses de las subsidiarias estadounidenses radicadas en este continente pasada una década.

$\mathrm{Su}$ iter, se enmarca a partir de ser reconocida por las Entidades Fiscalizadoras Superiores en el año 1995, como herramienta de gestión ambiental, aunque otros estudios contables se considere su génesis vinculada a la Contabilidad y a la Auditoría Social para dar respuesta a problemas generados al medio ambiente como la contaminación atmosférica, el vertido, la lumínica, la sonora; dirigida a la protección a la biodiversidad, el cambio climático, a los recursos hídricos, al incremento de los niveles de radiación, la lluvia ácida, el incremento de las concentraciones de ozono generado por la industria, la calidad del aire en las ciudades, el uso y manejo de la tierra, la desertificación, el comercio y el medio ambiente.

La década de los 90 adiciona nuevos elementos tecnológicos vinculados al comercio internacional,-hacen mucho más compleja, completa y dinámica la gestión ambiental por parte de los sujetos económicos que la implementan; así las cosas, las técnicas, métodos y objetivos de la auditoría como actividad de control de forma simétrica evolucionó para poder atender y dar respuestas a las nuevas exigencias de los clientes a partir del siglo XX hasta la actualidad en el mercado de bienes $\mathrm{y}$ servicios.

Son analizados conceptos dados sobre esta actividad de control por la Entidad Fiscalizadora Superior, y la define como la herramienta técnica de gestión para realizar la evaluación sistemática, documentada, periódica y objetiva de la efectividad de la organización auditada; la gerencia y los equipos ambientales para proteger el medio ambiente con un mejor control de las prácticas ambientales y la evaluación; para cumplir las políticas ambientales de la empresa y las normativas legales, a partir de la institucionalización de la tutela ambiental.

Las normas técnicas ambientales ISO 14001 y 19011 la definen como: "proceso sistemático, autónomo y documentado para obtener evidencias de la auditoría, evalúa de manera objetiva con el fin de determinar la extensión en que se cumplen los criterios de auditoría".

La Cámara Internacional de Comercio, la reconoce como: 
Herramienta de gestión que comprende una evaluación sistemática, documentada, periódica y objetiva del funcionamiento de la organización ambiental. Prevé la implantación de gestión, así como los equipos de control necesarios con objeto de facilitar el control de gestión de las prácticas medio ambientales y declarar la observancia de la política de la Compañía de acuerdo con la normativa medio ambiental. Es el examen metódico que implica análisis y comprobaciones de las prácticas y procederes ambientales de una empresa o parte de ella. Este término de auditoría es sinónimo de revisión y verificación de diversos aspectos de una empresa. $(1997)^{12}$

Como actividad de control, es el instrumento de gestión ambiental de naturaleza jurídica pública, su campo de acción son la empresa, la industria y el medio ambiente (personas jurídicas y naturales); su ejecución es realizada por funcionarios públicos requeridos de título profesional y un título habilitante, registrados en el Registro de Auditores y Contralores; su función es evaluadora y certificadora de las metas ambientales en relación con la política ambiental trazada por la organización empresarial, es una técnica de comprobación de la legalidad con una potestad reglada de la Administración Pública.

Es un proceso, en su práctica se utilizan procedimientos y metodologías, se evalúa la ejecución gasto contable del patrimonio destinado a la protección ambiental; puede ser ejecutada de forma interna o externa, se evalúa la eficiencia del sistema de gestión ambiental en relación con el vertido, la introducción de tecnologías limpias en la organización empresarial; se aplican normas técnicas; se exige la responsabilidad administrativa contravencional, laboral-funcionarial, socialempresarial, civil y penal a los sujetos auditados. Tiene efecto directo y vinculante al auditado, puede ser onerosa o gratuita. Su resultado final certificatorio le aporta valores añadidos que inciden de forma positiva en el comercio y el mercado a la persona jurídica o natural objeto de la auditoría.

Desde la doctrina jurídica Hispanoamericana consultada, académicos como De Bessa Antunes (2010), Di Trindade Amado (2011), Bustamante Alsina (1995), Caferrata (2003), Martín Mateo (1991), 
Jordano Fraga (2009), De Gatta Sánchez, Parejo Alfonso (2012), Sanz Rubiales (2007), y Nogueira López (2000), señalan en sus estudios realizados desde 1995-2014 que la auditoría ambiental como instrumento de gestión, comprende una evaluación sistémica, documentada, periódica, y objetiva del comportamiento de una organización empresarial, del sistema de gestión ambiental y de los procedimientos destinados a proteger el medio ambiente. Evalúa el cumplimiento de la política ambiental de la organización empresarial, sus objetivos y metas ambientales, y el control del impacto ambiental generado al medio ambiente.

Refieren estos autores que sus elementos caracterizadores se perciben a partir de que es un instrumento de gestión ambiental, evaluador de los índices de contaminación generados al medio ambiente, del cumplimiento de la legalidad, de la externalización e internacionalización de los costes ambientales integrándolos a la responsabilidad ambiental en la organización empresarial. Como instrumento de tutela ambiental, tiene carácter horizontal para adoptar estrategias de protección ambiental.

Su adhesión es voluntaria u obligatoria, proporciona y da publicidad sobre el comportamiento ambiental a la organización empresarial. Reseñan que es una técnica de protección ambiental. Está reconocida como un instrumento de mercado de carácter cooperador. Permite a la organización usar un logotipo como organización responsable tras el resultado de la auditoría y ello le permite que se inscriba en un Registro Público. Se constata, como se le regula en los ordenamientos jurídicos en su desarrollo interno a través de Leyes de Auditoría, de Contraloría, de Gestión Ambiental, de Medio Ambiente y de Responsabilidad Ambiental por su especialidad.

El fin de esta actividad de control es prevenir, perfeccionar la tecnología y dar un carácter más competitivo con influencia mercantil, al conceder la certificación ambiental. En la Declaración de Johannesburgo de 2002, se reafirmó este compromiso. Son medidas que pretenden crear incentivos al mejor cumplimiento de las normas ambientales mediante el uso de instrumentos económicos y fiscales "ecoetiquetas", "ecoauditorías", "ecotasas", y otras. Su evolución como actividad de control ha trascendido desde la empresa al sector industrial con las EMAS y finalmente hacia la biodiversidad, al cambio climático y a los recursos hídricos en la primera década del siglo XXI con las auditorías de gestión ambiental. 


\section{LOS PUNTOS DE CONTACTO DE LOS INSTRUMENTOS DE GESTIÓN AMBIENTAL}

Se justiprecia que los puntos de contacto que permitirán coadyuvar a alcanzar el desarrollo sostenible, y con ello lograr la adecuada tutela del bien jurídico ambiente, concebido como la base de la categoría de los instrumentos de mercado de carácter cooperador-, al compatibilizarse la tutela ambiental con el crecimiento económico, al decir del de autores como Martin Mateo (1994), Kiss, Shelton, Villamil Serrano, Maties García, Steward, y Piñar Mañas.

Se confirma con la implementación de las políticas en materia de protección ambiental con una gestión ambiental adecuada (política, derecho y administraciones ambientales), los métodos de control público ambiental aplicados para su tutela, la relación del Derecho Ambiental con otras ramas del Derecho, en especial con el Administrativo por ser el eje trasversal y con otros saberes por su interdisciplinariedad y multidisciplinariedad, permitirán alcanzar la meta del desarrollo sostenible; lo refrendan los estudios desarrollados por Parejo Alfonso (1998), Embid Irujo (1999), Jordana de Pozas, Betancor Rodríguez (2001), Mora Ruiz(2007), y Lozano Cutanda (2004).

En este escenario de control público ambiental, aparecen como sujetos el Ministerio del Ambiente y la Contraloría General (uno dentro del entramado de la Administración Pública y otro como un órgano de control superior), los que darán continuación al fomento de esta actividad para reforzar con ello la protección al bien tutelado ambiente a través de las funciones clásicas de la inspección y la auditoría, reconocidas desde la doctrina administrativa como la noción estricta de gestión del medio ambiente, articulándose a través de una actividad de control y de limitación; es aquí donde se reconoce la orientación del Derecho Administrativo Ambiental, al darle entrada a los instrumentos de mercado de carácter cooperador, señalado por Martin Mateo (1997), Mora Ruiz (2012), Parejo Alfonso (2013), Fernández de Gatta Sánchez (2008), Bustamante Alsina (2008) y Nogueira López (1997). ${ }^{13} \mathrm{Su}$ finalidad es premiar las actuaciones que van más allá de las normas de obligado cumplimiento.

13Ver: MARTÍN MATEO, Ramón, Derecho Administrativo Ambiental, $6^{\text {ta }}$ edición, Editorial Trivium, España, 1997; MORA RUÍZ, Manuela, “Tendencias del Derecho Administrativo. El Derecho Administrativo Ambiental: transformaciones en el Derecho Administrativo general" en, Revista Derecho y Conocimiento, España, 2012; PAREJO ALFONSO, Luciano, El derecho al medio ambiente y la actuación de la Administración Pública, Editorial Aranzadi, España, 2013; FERNÁNDEZ DE GATTA SÁNCHEZ, Dionisio, Las auditorías ambientales, Editorial Tirant lo Blanch, España, 2008; BUSTAMANTE ALSINA, Jorge, La ecoauditoría empresarial en la Unión Europea, Editorial Abeledo Perrot S.A., Argentina, 2008; NOGUEIRA LÓPEZ, Alba, Tesis Doctoral: Régimen jurídico de la auditoría ambiental, Universidad Santiago de Compostela, España (1997). 
El control público en la protección ambiental, se distingue de la función inspectiva al evaluar los procesos contables en materia ambiental en relación con el patrimonio financiero destinado a estos fines y la evaluación de la eficiencia y eficacia de los sistemas de gestión ambiental en el sector industrial, tal y como lo conciben autores como Font Llovet, Parada, Jordana de Pozas(1951), Embid Irujo (2010), Macera, Canals I Ametller, Arena, Nogueira López (2010), Ramírez Sánchez y Antúnez Sánchez (2015). ${ }^{14}$

La inspección ambiental, dirigida en esencia al control de los ecosistemas de interés, en materia de vertidos al dominio público hidráulico, en cuencas hidrográficas o en materia de vertidos al dominio público marítimo-terrestre, participa en el control de las empresas, industrias o actividad, les certifica el cumplimiento de la normativa ambiental $^{15}$, concediendo la etiqueta ambiental a los productos y servicios evaluados, y el aval ambiental. La función inspectora tiene un alto coste en los medios personales y equipamientos que son utilizados en su aplicación e implementación. Ya se trate de actuaciones programadas o no rutinarias, la inspección, por su propia naturaleza, siempre actúa de oficio. Como los derivados del principio de proporcionalidad y, específicamente, en el caso de los requerimientos de información, del Derecho Constitucional a declarar contra uno mismo.

También aparece el principio de -responsabilidad compartida-, el que se deberá configurar como el principio instrumental de una tutela ambiental renovada, donde se impone revisar las relaciones entre la Administración Ambiental y los ciudadanos, ello permitirá alcanzar una participación más amplia y activa de los agentes económicos, de los poderes públicos, de los sujetos de gestión y del público en general -

14 Ver: JORDANA DE POZAS, Luis, El problema de los fines de la actividad administrativa, en Revista de Administración Pública, número 4, España, 1951; EMBID IRUJO, Antonio, Precaución y Derecho, Editorial Iustel, Madrid, 2010; NOGUEIRA LÓPEZ, Alba, "Hacia un EMAS de alcance internacional en competencia con la ISO 14001: notas a la revisión del Reglamento EMAS" en, Revista electrónica Actualidad Jurídica Ambiental, España, 2010, Disponible en:http://www.actualidadjuridicaambiental.com (Consultado en fecha 24 de noviembre de 2016); RAMÍREZ SÁNCHEZ, Amed, y ANTÚNEZ SÁNCHEZ, Alcides, $L a$ responsabilidad administrativa derivada de la inspección estatal sanitaria en Cuba. Una mirada a su régimen jurídico sancionador desde la lucha contra el dengue, Revista Derecho y Cambio Social, Perú, 2015;

15 Ver: FERNÁNDEZ RAMOS, Severiano, La inspección ambiental, en Medio Ambiente y Administración Local, España, 2012, pp.1-26; ALENZA GARCIA, José Francisco, Potestad de inspección, en Revista Actualidad Jurídica Ambiental, España, p.1894; AMENÓS ÁLAMO, Juan, La inspección urbanística: concepto y régimen jurídico, Editorial CEDECS, Barcelona, 1999, pp. 198-236; BERMEJO VERA, José, La Administración Inspectora, en Revista de Administración Pública, número 147, Centro de Estudios Políticos y Constitucionales, España, 1998,pp.1-20; ESTEVE PARDO, José, De la policía administrativa a la gestión de riesgos, Revista Española de Derecho Administrativo, número 119, España, 2003; GARCIA URETA, Agustín, Potestad inspectora y medio ambiente: Derecho de la Unión Europea y algunos datos sobre las Comunidades Autónomas, Revista Actualidad Jurídica Ambiental, número 54, España, 2016, pp.1-36; GUILLÉN CARAMÉS, Javier, Régimen jurídico de la inspección en Derecho de la competencia, Editorial Aranzadi Thomson Reuters, Cizur Menor, 2010, pp.237-260; MIRANDA HERNÁNDEZ, Gloria, La potestad inspectora de las Administraciones Públicas en, Revista Cuadernos de Inspección del Territorio, España, 2012, pp.1-21; REBOLLO PUIG, Manuel, La actividad inspectora, Editorial Iustel, España, 2011. 
ciudadanos y consumidores- y por qué no, la Universidad como el ente formador (ya no solo es ejecutada la actividad de control -inspección y auditoría- por la Administración Pública, es ejecutada por ciudadanos habilitados para este fin).

La Evaluación de Impacto Ambiental, vinculada a la inspección ambiental, es el paso previo para su ejecución, al evaluar los supuestos de riesgo grave para el medio ambiente como institución jurídica ponderando el principio de prevención. Está concebida como una técnica de coordinación entre organismos de una misma Administración Pública por su interdisciplinariedad, los que dan un informe evaluatorio, sobre la protección de la salud, riesgos industriales, salud laboral, medio ambiente construido, desechos peligrosos por vertido, contaminación atmosférica, lumínica, ruido; en este proceso participan otros cuerpos de inspección, en materia de salud, urbanístico, seguridad laboral, entre otros; tiene dos pasos previos, uno es el estudio de impacto ambiental que concluye con el informe evaluatorio y el otro la declaración de impacto ambiental con un carácter público. En sí, es el acto administrativo definitivo del órgano ambiental por el que se determina la conveniencia o no de realizar el proyecto y fija las condiciones que deben establecerse en orden a la adecuada protección del medio ambiente. De aquí que el paso siguiente será otorgarse o no la licencia ambiental, por ser un trámite cualificado de juicio materialmente autorizatorio, requerido de cierta onerosidad en los trámites administrativos en la materia ambiental.

La Evaluación Ambiental Estratégica, es una herramienta preventiva, permite completar el proceso de evaluación ambiental en la jerarquía de decisiones, es más integral, evalúa todas las decisiones estratégicas para lograr el desarrollo sustentable; es sistémica. La misma incluye ocho elementos: "la investigación, el ámbito obligatorio, el ámbito no obligatorio, alcance, evaluación de alternativas, informe ambiental, consultas, toma de decisiones, información sobre la decisión y supervisión" (Gómez, 2010). ${ }^{16}$

\section{AMANERADE CONCLUSIÓN}

Los puntos de contacto de los instrumentos ambientales como la Evaluación de Impacto Ambiental, la Inspección Ambiental, la Licencia Ambiental y la Auditoría Ambiental tienen como el elemento clave la prevención como principio del Derecho Ambiental, visto y aplicado desde una perspectiva del sector empresarial industrial; más que la reparación Politécnica de Madrid (2010); FERNÁNDEZ DE GATTA SÁNCHEZ, Dionisio, "El régimen jurídico de las Evaluaciones de Impacto Ambiental, las Evaluaciones Estratégicas y las Auditorías ambientales" en, 
por el daño ambiental, lograda con una gestión ambiental adecuada y mayor responsabilidad con el acatamiento de la normativa ambiental, al aplicarse de manera adecuada la Responsabilidad Social Empresarial.

En la ejecución de los instrumentos ambientales como la Evaluación de Impacto Ambiental, la Inspección Ambiental, la Licencia Ambiental y la Auditoría Ambiental como instituciones jurídicas reconocidas en ley, decreto o reglamentos; los mismos aplican procesos y procedimientos, predomina la interdisciplinariedad y transdisciplinariedad por sus ejecutantes por la multidimensionalidad de la cuestión ambientalista en la protección del bien público ambiente, como parte de la política ambiental para la implementación de la gestión pública ambiental para alcanzar el desarrollo sostenible como res comunes.

La triada Evaluación de Impacto Ambiental, Inspección Ambiental y Licencia Ambiental, no es complementada por la Auditoría Ambiental, esta actividad de control es el instrumento de gestión más integrador, toda vez que evalúa las acciones realizadas en la Evaluación de Impacto Ambiental, la Inspección Ambiental y la Licencia Ambiental otorgada, si se han cumplido todos los requerimientos técnicos y el principio de legalidad por sus ejecutores, hace una evaluación del cumplimiento de los procedimientos contables en relación con las acciones ejecutadas y si se actuó conforme a Derecho del patrimonio presupuestario destinados a la protección ambiental, como del sistema de gestión ambiental en funciones.

La inspección y la auditoría ambiental, tienen elementos en común que las definen como actividad de control, pero difieren en la institución que las ejecuta y los procesos y procedimientos para su contextualización por el cuerpo de inspectores y auditores, es realizada por sujetos estatales y privados.

La ciencia económica aportó tres elementos para el estudio de la problemática ambiental, su naturaleza de recursos extractivos, la calidad de vida, y la contaminación. Esta última, calificada como el abuso de la capacidad asimilativa del medio ambiente, en cuanto vertedero de residuos y desperdicios, es aquí donde entran a jugar un rol preponderante de los instrumentos de gestión analizados.

\section{REFERENCIAS BIBLIOGRÁFICAS}

AA. VV. Derecho al Medio Ambiente y Administración Local, obra coordinada por ESTEVE PARDO, José, $2^{\text {da }}$ edición, Editorial Fundación Democracia y Gobierno Loca, España, 2006. 
Álvarez, C. (2008). Sistemas de certificación ambiental para la extensión tecnológica, la competitividad empresarial. Revista $P+L$. Colombia.

Alvarado, M. (2014). Teoría y práctica de la auditoría. España: Editorial Pirámide.

Alonso, E. (1989). La participación de individuos en la toma de decisiones relativas al medio ambiente en España. Aspectos constitucionales. R.E.D.A, 61, 43-65.

Alli, J. (1989). Régimen Jurídico de la Evaluación de Impacto Ambiental. Revista Jurídica de Navarra, 8, 69-117

Antúnez, A. (2016). La potestad inspectiva v/s auditoría pública. Ojeada histórica dentro del Derecho Administrativo Ambiental cubano. Revista Dos Tribunais Thomsonreuters, 967. Recuperado de hptt://www.thomsonreuters.com

Antúnez, A. (2015). La auditoría de gestión ambiental a los recursos hídricos, a la biodiversidad y al seguimiento del cambio climático. Revista del Tribunal de Cuentas, 132.

Andaluz, C. (2006). Manual de Derecho Ambiental. Perú: Editorial Proterra.

Amenós, J. (1999). La inspección urbanística: concepto y régimen jurídico. Barcelona: Editorial CEDECS.

Armisén, J. (2008). Concepto, alcances y resultados actuales de la auditoría ambiental. Revista UNAM.

Arteag, K. (2015). Ecogestión y Ecoauditoría, un instrumento de protección medio ambiental. (Tesis de Maestría). Facultad de Derecho, Universidad Complutense de Madrid, España.

Audiverti, R. (1997). Régimen jurídico de la etiqueta ecológica. España: Editorial CEDECS.

Ayes, A. (2003). Medio Ambiente, impacto y desarrollo. La Habana: Editorial Científico-Técnica.

Belmonte, I. (2010). La ecoauditoría: instrumento para la defensa del medio ambiente. Revista electrónica de la Facultad de Ciencias Jurídicas y Sociales de Elche. 
Bellorio, D. (1997). Tratado de Derecho Ambiental.Argentina: Editorial ADHOC.

Bermejo, J. (1998).La Administración inspectora. Revista de Administración Pública, 147.

Betancor, A. (2001). Instituciones de Derecho Ambiental. Madrid: Editorial La Ley.

Bifaretti, M. (2008). Contabilidad de gestión: la importancia de los costos ambientales en el sistema de información contable. Argentina: Editorial D\&R Profesional y Empresarial.

Carmona, M. (2005). Aspectos jurídicos de la auditoría ambiental en México. Revista UNAM.

Cánovas, D. (2010). Licencia ambiental y sistemas de responsabilidad. En Álvarez, A y Mantilla, A (coords.). El Derecho Público en Cuba a comienzos del siglo XXI. Editorial de la Universidad de La Habana.

Conesa, V. (1997). Auditorías medio ambientales: guía metodológica. España: Editorial Mundi-Prensa.

Da Conceição, M. (2012). La problemática de la auditoría ambiental. Revista Empresarial

Da rocha, R. (2012). Direito ambiental: doutrina e casos práticos. Brasil: Editorial Elselvier.

Darnaculleta, I., \& Gardella, M. (2005). Autorregulación regulada y medio ambiente. El sistema comunitario de ecogestión y auditoría ambiental. Revista Derecho del Medio Ambiente y Administración Local, España

Díaz, A. (1999). Propuesta de metodología para la realización de auditorías de gestión basada en el elemento ecológico. (Tesis de Maestría). Universidad de Zaragoza, España.

Di Cagno, V. (2005). La protección del medio ambiente en Cuba. La Habana: Editorial Ciencias Sociales.

Domper, J. (1992). El medio ambiente y la intervención administrativa en las actividades clasificadas. volumen I y II. Madrid: Editorial Cívitas. 
Elstein, S. (2012). La auditoría del medio ambiente crece y evoluciona para afrontar los retos de un ambiente cambiante. Revista de Auditoría Gubernamental, INTOSAI.

Embid, A. (1999). El rol del Estado: Vigilante o Gestor. Revista de Politica Ambiental y Desarrollo Sostenible

Fernández de Gatta, D. (2008). Las auditorías ambientales. España: Editorial Tirant lo Blanch.

Fernández de Gatta, D. (2013). El régimen jurídico de las evaluaciones de impacto ambiental, las evaluaciones estratégicas y las auditorías ambientales. Revista Aragonesa de Administración Pública, 41.

Fernández de Gatta, D. (2010). El séptimo programa ambiental de la Unión Europea 2013-2020. Revista Aragonesa de Administración Pública, 42.

Fernández, S. (2010). La inspección ambiental. Revista del Medio Ambiente y la Administración Local.

Fernández, S. (2002). La actividad administrativa inspectora. El régimen jurídico general de la función inspectora. Granada: Editorial Comares.

Fernández-rubio, A. (1991). Instrumentos Jurídicos Internacionales. La Habana: Editorial Pueblo y Educación.

Ferrer, P. (2006). Perspectiva jurídico financiera del medio ambiente. (Tesis Doctoral). Universidad Pompeu de Fabra, España.

García, J. (2014). La inspección ambiental y el derecho comunitario europeo. Revista Ambiente \& Derecho, 26-27.

García, A. (2016). Potestad inspectora y medio ambiente: Derecho de la Unión Europea y algunos datos sobre las Comunidades Autónomas. Revista Actualidad Jurídica Ambiental, 54.

García, J., \& Rey, O. (2005). Foros de negociación e instrumentos jurídicos internacionales en materia de medio ambiente $y$ desarrollo sostenible. La Habana: Editorial Acuario.

Gómez, D. (1994). Auditoría ambiental: un instrumento de gestión en la empresa. España: Editorial Agrícola Española. 
Gómez, M. (2010). Evaluación Ambiental Estratégica Tesis Doctoral). Universidad Politécnica de Madrid, España.

Gonzále, J. (2011). La naturaleza jurídica del Impacto Ambiental. Análisis de Derecho comparado, México: Editorial Imida.

Heras, I. (2008). Evolución al reglamento de las EMAS en la Unión Europea y España. Revista Ambienta, Universidad del país Vasco.

Jordano, J. (2010). Viejos y nuevos retos de la Evaluación de Impacto Ambiental. Revista Derecho y Medio Ambiente.

Lutosa, C. (2014). Las auditorías coordinadas y sus contribuciones para los Estados Federales: la experiencia de la auditoría en la Amazonía. Revista OLACEFS, 15.

López, J. (1990). El régimen jurídico de la Evaluación de Impacto Ambiental. R.A.A.P, 4, 61-91.

Lorenzetti, R. (2008) Teoría del Derecho Ambiental. México: Editorial Porrúa, México.

Lozano, B. (2004). Derecho Ambiental Administrativo. (5ta ed.). Madrid: Editorial Dykinson.

Lozano, B. (2015). Tratado de Derecho Ambiental. España: Editorial CEF.

Martín, R. (1991). Tratado de Derecho Ambiental. Madrid: Editorial Trivium.

Martín, R. (1993). La ecoauditoría. Boletín de Estudios Económicos, 150.

Martí, R. (1994). Nuevos Instrumentos para la Tutela ambiental. España: Editorial Trivium.

Mora, M. (2012).La gestión ambiental compartida: función pública y mercado. (1ra ed.). España: Editorial Lex Nova

Morena, J. \& Plaza, C (coord.). (2003).El Etiquetado Ecológico: Verde por Dentro, Vende por Fuera. Madrid: Editorial Medio Ambiente. 
Moreno, R. (1993).Régimen Jurídico de la evaluación de impacto ambiental.Madrid: Editorial Trivium.

Morales A. (2007). Estudios de Derecho Ambiental. Argentina: Editorial Alveroni.

Moya, F. (2013). El principio de precaución. Chile. Editorial Cuadernos del Tribunal Constitucional.

Murad, P. (2009). La auditoría ambiental voluntaria, concepto, antecedentes, fundamentación jurídica y evaluación. México: Editorial Porrúa.

Nogueira, A. (2007). Régimen jurídico de la auditoría ambiental. (Tesis Doctoral)". Universidad Santiago de Compostela, España.

Nogueira A. (2010). Hacia un EMAS de alcance internacional en competencia con la ISO 14001: notas a la revisión del Reglamento EMAS. Revista electrónica Actualidad Jurídica Ambiental. Recuperado de http://www.actualidadjuridicaambiental.com

Nogueira, A. (2010). Ecoauditorías, intervención pública ambiental y autocontrol empresarial. España: Editorial Marcial Pons.

Núñez, C. (2011). Bases conceptuales de los derechos ambientales y transgeneracionales. Revista de Derecho UNED, 8.

Padin, M. (2011). La auditoría ambiental y las normas ISO 14000. Revista Foro de Contabilidad Ambiental y Social, 5, Argentina.

Parejo, L. (1998). El Derecho Medio Ambiental en la Unión Europea. México: Editorial Mac Graw Hill

Pérez, A. (1993).Instrumentos de tutela ambiental.España: Editorial Trívium.

Pereira, J. (2011). La autorización ambiental en el marco del procedimiento de evaluación de impacto ambiental: introducción a su régimen jurídico en Cuba. (Tesis de Maestría). Facultad de Derecho, Universidad de La Habana, Cuba.

Pigreti, E. (2007). Ambiente y Sociedad. El bien común planetario. Buenos Aires: Editorial Lajouane. 
PNUMA. (1993). Propuesta de Ley Básica de protección ambiental y promoción del desarrollo sostenible. Serie de Documentos sobre Derecho Ambiental, 1, México.

PNUMA. (1995). Hacia un Sistema para la formación en Derecho Ambiental. Serie de Documentos sobre Derecho Ambiental, 3, México.

Prieur,M. (2003). Derecho del Medio Ambiente. (5 $5^{\text {ta }}$ ed.). Paris: Editorial Dalloz-Sirey.

Núñez, Cayetano, Bases conceptuales de los derechos ambientales y transgeneracionales, en Revista de Derecho UNED, número 8, España, 2011.

Quintana, T. (2014). Evaluación de impacto ambiental y evaluación estratégica. España: Editorial Tirant lo Blanch.

Razqui, J. (2000). La Evaluación de Impacto Ambiental. Navarra: Editorial Aranzadi.

Rebollo, M. (2004). La alta inspección, La reforma del Sistema Nacional de Salud. en, Parejo, L (coord..). España: Editorial Marcial Pons.

Rebollo, M. (2011). La actividad inspectora. España: Editorial Iustel.

Revuelt, I. (2001).Las nuevas tendencias en la inspección ambiental de actividades industriales. Revista de Derecho Urbanístico y Medio Ambiente, 185.

Rodríguez, R. (2016). La auditoría ambiental en la gestión empresarial. Holguín: Editorial Colciencias.

Rinaldi, G. (2013). La evaluación de impacto ambiental estratégica, nexo con la auditoría ambiental en, PNUMA-ONU.

Sardone, A. (1988). Valutazione di Impatto Ambientale in USA. Regulations N.E.P.A. Milano: Editore Clup.

Santamaría, R. (2006). Implicaciones del Desarrollo Sostenible para la Ciencia del Derecho Administrativo. Revista Donostia, 631-638.

Sanz, I. (2000). Sobre la naturaleza jurídica de la etiqueta ecológica. España: Editorial Marcial Pons. 
Soto, R. (2012). La auditoría ambiental y su proceso en el contexto de la auditoría integral. Revista Ciencia y Desarrollo, 3.

Silva, B. (2012) Evaluación ambiental: impacto y daños. Un análisis jurídico desde la perspectiva cientifica. (Tesis Doctoral) Universidad de Alicante, España.

Sunkel, O., \& Leal, J. (1985). Economía y Medio Ambiente en la perspectiva del Desarrollo. Revista Ambiente y Recursos Naturales, 1

Stewart, R. (1988). Controlling Environmental Risks Through Economic Incentives. Columbia Journal of Environmental Law, 2,153-169.

Stewart, R., \& Ackerman, B. (1988). Reforming Environmental Law, The Democratic Case for Market Incentives. Columbia Journal of Environmental Law, 2, Estados Unidos deAmérica, 171-199.

Tarrés, M. Los sujetos privados en la gestión y auditoría medio ambiental comunitaria. Su desarrollo en la Ley ambiental alemana. Revista de Administración Pública, 145.

Irribaren, F. (2010). Evaluación de Impacto Ambiental. Argentina: Universidad de la Patagonia.

Van, S. (2013). El desarrollo de la auditoría ambiental dentro de la INTOSAI. Revista Internacional de Auditoría Gubernamental, 1.

Villacorta, A. (2012). Ecoauditoría: una necesidad actual. Revista de la Asociación Interamericana de Contabilidad.

Villarino, T. (2010). Curso de evaluación de impacto ambiental. Madrid: Instituto de Territorio, Paisaje, Ambiente y Sostenibilidad, Editorial ITEPAS.

Villavella, C. (2011). Los derechos humanos y el medio ambiente su tratamiento en el Derecho Constitucional comparado. Revista electrónica de estudios jurídicos CUBALEX, Unión Nacional de Juristas de Cuba,.1-10. Recuperado de hptt//www.cubalex.cu

Verdes, Y. (2014). Las etiquetas ambientales. Régimen jurídico del etiquetado ecológico. (Tesis de Maestría). Universidad de la Coruña, España. 


\section{Disposiciones jurídicas internacionales consultadas:}

Organización de las Naciones Unidas. (1972). Declaración de la conferencia de las Naciones Unidas sobre el medio ambiente humano.

Organización de las Naciones Unidas. (1972). Declaración de Estocolmo.

Organización de las Naciones Unidas. (1982). Carta Mundial de la Naturaleza, ONU, 1982.

Organización de las Naciones Unidas. (1992). Convenio sobre la diversidad biológica.

Organización de las Naciones Unidas. (1992). Declaración de Rio, sobre el medio ambiente y el desarrollo.

Organización de las Naciones Unidas. (1992). Programa de Naciones Unidas para el Medio Ambiente. Agenda 21.

Organización de las Naciones Unidas. (1997). Protocolo de Kioto.

Organización de las Naciones Unidas. (2002). Declaración de Johannesburgo sobre el desarrollo sostenible.

Organización de las Naciones Unidas. (1991). Convención Espoo, Evaluación de Impacto Ambiental.

Organización de las Naciones Unidas. (2008). Protocolo sobre Evaluación Ambiental Estratégica.

Organización de las Naciones Unidas. (2015). Convención sobre el Cambio Climático, París.

Organización de las Naciones Unidas. (2015). Agenda 2030 para el desarrollo sostenible.

Organización de las Naciones Unidas. 20 a 22 de junio de 2012). Declaración Rio+20. Recuperado de https://rio20.un.org/sites/ rio20.un.org/files/a-conf.216-1-1_spanish.pdf.pdf 